Open Access

\title{
Labeling food safety attributes: to inform or not to inform?
}

\author{
Kofi Britwum ${ }^{1 *}$ (1) and Amalia Yiannaka ${ }^{2}$
}

\author{
* Correspondence: kofi.britwum@ \\ maine.edu \\ ${ }^{1}$ Postdoctoral Research Associate, \\ School of Economics, University of \\ Maine, 5782 Winslow Hall, Orono, \\ ME 04469, USA \\ Full list of author information is \\ available at the end of the article
}

\begin{abstract}
We examine the impact of food labels that make unsupported claims of food safety and labels that provide information to support such claims on consumer choices and examine consumers' willingness to pay for beef products with these different food safety labeling cues. Empirical results from a survey of grocery shoppers in a Midwestern city in the USA show that more than two thirds of respondents who received a label with unsubstantiated food safety claims chose this option and were willing to pay the highest price premium for it, compared to the less preferred labeling options that provided information to support food safety claims.
\end{abstract}

Keywords: Food labels, Ground beef, Survey, Vaccines against E. coli, Willingness to pay

JEL Codes: D12, Q13, Q18

\section{Introduction}

Food labels have gradually evolved from simply conveying nutritional information to communicating the presence of desirable or the absence of undesirable food attributes and/or production technologies. The development of several niche food markets has been enabled by labels highlighting the existence of positive or the absence of "negative" food attributes and/or technologies, effectively targeting consumers valuing this type of information. Examples include the "All Natural," "No Growth Promoting Antibiotics," "No GMOs," “Cage-free,",and "rBST-free” food labeling claims.

Evidence that consumers value and are willing to pay for such labels abounds. Wang et al. (1997) found that consumers concerned about rBST use in dairy production were also willing to pay more for the rBST-free label. Kanter et al. (2009) showed that having rBST-free milk reduced willingness to pay (WTP) for conventional milk by as much as $33 \%$, after participants had been introduced to information about rBST-free milk.

There is also evidence that consumers are concerned about and are willing to pay price premiums for healthy, safe, and superior quality foods (Loureiro and McCluskey 2000). Verbeke and Ward (2006) reported that beef labeling cues that were rated as important by consumers were those related to perceived meat quality and safety. Dolgopolova and Teuber (2017), in a meta-analysis of consumer valuation of healthy food attributes, report positive WTP amounts for healthy food attributes and claims. Bimbo et al. (2016) showed that consumers were willing to pay price premiums for food attributes perceived to enhance health, such as "organic" and "natural". Syrengelas et al. 
(2017) found that consumers were willing to pay price premiums for the "natural" claim in steaks even though they did not know the United States Department of Agriculture (USDA) interpretation of this claim. In a study that examined British and German consumers' valuation of beef safety attributes, Lewis et al. (2017) reported that consumers were willing to pay a price premium for "hormone-free" beef, an attribute viewed as a beef safety cue. In addition, this study found that the country of origin was an important consideration among consumers who placed a high value on food safety, purportedly because it was perceived as another food safety signal (Lewis et al. 2017).

Several studies have also found that consumers are willing to pay for specific food safety technologies. Nayga Jr et al. (2006) examined consumer preferences for irradiated beef and found a WTP premium of 77 cents for a pound of irradiated ground beef, amounts considered adequate to cover the cost of the technology on a commercial scale. Huang et al. (2007) reported that consumers in the US state of Georgia were open to the use of irradiation in foods, with $65 \%$ of them expressing intent to purchase.

Despite consumer expectation of ${ }^{1}$ and preference for safer food, foods produced with unique food safety enhancing interventions have been rather challenging to differentiate in the market. This challenge stems in part from consumer misapprehension of the technologies adopted to ensure safer food products, and in part also due to food labeling claims that are uninformative or ambiguous, and the use of terms that do not have standardized interpretations (Palma et al. 2015). Thus, even though evidence from research studies shows that consumers are willing to pay and are accepting of certain food safety enhancing technologies when they are provided with information about their potential beneficial effects, the challenge is how to effectively communicate such technologies on food labels and how much information to provide on a label to substantiate food safety claims. This is particularly so for technologies consumers may be unfamiliar with (e.g., nanotechnology), or technologies not yet introduced.

The primary goal of this study is to examine the impact of different ways of communicating food safety attributes on consumer choices and WTP for various food safety labeling cues on food products. Secondary goals include examining how factors such as demographic characteristics, personal health issues, knowledge and acceptance of food safety interventions, and views about the government's role in regulating and ensuring food safety influence consumer preferences and WTP for food safety labels.

The food labels used in this study include both vague, unsubstantiated claims of food safety and more precise descriptions of a food safety enhancing technology to test the hypothesis that uninformative or ambiguous food labels with a positive message may resonate more powerfully with consumers than labels that provide factual information to corroborate food safety claims. The food safety enhancing technology considered is cattle vaccines against virulent strains of $E$. coli, a technology that has not seen widespread adoption.

Focusing on a technology that the public may be unfamiliar with and/or apprehensive about, the case study contributes to the literature by exploring different ways by which health claims attributed to the food safety intervention may be presented on food labels. Specifically, previous literature elicited bidding behavior/WTP for food safety attributes by providing respondents with different types of information such as negative and/or positive information (Fox et al. 2002; Nayga Jr et al. 2006; Teisl and Roe 2010). Our study extends the literature by examining and comparing food safety labels that 
use vague food safety claims to labels that include more precise descriptions of a food safety intervention to substantiate these claims without providing any additional information about the nature of the food safety intervention. By tweaking the description of health claims on food product labels, the study closely gauges labeling preferences with a design that matches an actual food purchasing scenario between competing product choices.

The rest of the study consists of five sections. The "Case study and experimental design" section describes the case study and experimental design used in the survey, followed by a description of the empirical models in the "Empirical models" section. The "Results and discussion" section discusses the model findings, and the "Conclusions" section concludes the study.

\section{Case study and experimental design}

The case study investigates consumers' response to and their labeling preferences for beef products from cattle vaccinated against virulent strains of $E$. coli such as $E$. coli O157:H7. Vaccines against E. coli O157:H7 have been approved for use by the USDA, have been shown to be effective in reducing the incidence of the bacteria in cattle by as much as $80 \%$ (Hurd and Malladi 2012), and can potentially decrease human cases of $E$. coli infections by at least $85 \%$ (Matthews et al. 2013). Notwithstanding the evidence supporting their effectiveness, they have received only limited adoption by beef producers (Callaway et al. 2009). This is partly attributable to the cost of the recommended application of the vaccine intervention, which can potentially erode producer surpluses if not matched by an increase in demand (Tonsor and Schroeder 2015). For this reason, capturing a price premium for beef products produced with this food safety intervention makes their differentiation in the retail market particularly pertinent for producers and processors.

However, signaling food safety attributes through food labels, and more so in the case of vaccines against $E$. coli can be potentially difficult for two reasons. First, the word "vaccine" on a food label may elicit mixed reactions among consumers, from concerns about drug resistance to the skepticism surrounding the long-term effect of vaccinations held by some. The second challenge involves indicating the name of a contaminant such as $E$. coli on a beef label, which may be subject to diverse interpretations. In this context, an important consideration is whether various consumer segments would perceive food safety claims to be credible, depending on how the claims are presented on food labels. Strijbos et al. (2016) noted that although health claims on meat with low nitrate levels were viewed as credible, trust varied by consumers' level of education; those with lower educational backgrounds were more likely to believe the claims.

A hypothetical survey was developed to address the above issues and achieve study objectives. The hypothetical nature of the survey was dictated by the fact that beef products from cattle treated with vaccines against E. coli $\mathrm{O} 157$ are not widely available in the market. Shoppers at five different grocery stores in Lincoln, Nebraska, were recruited to participate in the survey between December 2016 and January 2017, yielding a total of 445 participants who were also beef consumers. The stores include three local grocery brands, a Midwestern chain, and a cooperative natural foods store. The different grocery store brands and locations were selected to capture responses from diverse backgrounds. ${ }^{2}$ The survey, which was designed using the Qualtrics software, took 
participants about $7 \mathrm{~min}$ to complete on a laptop computer, and each store session lasted approximately $5 \mathrm{~h}$. A session began by setting a table and laptop computers in a heavily trafficked part of the store and by asking shoppers whether they were beef consumers, and if so, whether they would be willing to participate in a brief survey and earn a $\$ 15$ store gift card.

The main part of the survey involved asking participants to choose between ground beef with a "standard" label (i.e., found on a typical ground beef product) and one that, in addition to the standard label, had a second label with food safety information. Three versions of the food safety labels were designed. The first showed the phrase "Safer Choice" in a circle with a description below indicating that the product is "from cattle raised under strict health standards to ENHANCE beef safety". In this version, no evidence is provided to support the food safety claim. We refer to this version as the "uninformative" or "unsubstantiated claim" version (Safer Choice/Enhance hereafter). The second food safety label showed the same "Safer Choice" phrase with accompanying information describing the product as originating "from cattle vaccinated against E. coli to REDUCE the risk of illness" (Safer Choice/Vaccinated hereafter). The third label showed the word E. coli in a red circle with a diagonal strikethrough to buttress the product's safety from $E$. coli bacteria and with a description below identical to the second food safety label (E. coli/Vaccinated hereafter). The $E$. coli with the slash-through design for the third label was intended to mimic other "free of" labels such as "No Growth Promoting Antibiotics" and "No Hormones," without explicitly claiming, however, that the product is entirely free of E. coli bacteria.

Each of the food safety labels was displayed to the left of the standard label on the ground beef product. The survey was designed such that participants were randomly assigned to one of the three food safety labeling options, with approximately 150 participants in each group. Thus, each participant saw only one (of the three) food safety label and had to choose among three options: ground beef with the standard label (option A), ground beef with the standard plus a food safety label (option B), and a "will not purchase either" option. To reflect food labels in an actual retail store setting, and to solely examine consumers' response to the food labels, no additional information about E. coli or vaccines were included in the survey. In making the initial choice between the ground beef in options A and B, no price information was given. The goal here was to have respondents choose between these two ground beef labels without being influenced by their prices. The food labels used in the survey are shown in section A of the Appendix. In addition to the labeling choices, the survey gathered information about participants' knowledge and opinions of animal production practices, beef consumption habits, views about the government's role in regulating and ensuring food safety, and demographic characteristics.

To determine WTP premiums for the ground beef with the additional food safety label, participants who chose option B (the standard label plus the food safety label) answered follow-up questions using the double-bounded contingent valuation (DBCV) elicitation format which presented two random premium bid amounts, with the second bid contingent on the first, following Hanemann et al. (1991). By asking the second question, the DBCV uses more information to determine WTP values, which improves the efficiency of the estimation (Hanemann et al. 1991). 
Respondents who chose option B were assigned a random premium bid amount over the base price of conventional ground beef (option A) which was given as $\$ 4.30$, and were asked whether they would be willing to pay this premium in addition to the original price for a pound of ground beef with the food safety label. If they answered Yes to the first premium bid, they were asked about their willingness to pay an amount greater than the initial bid. If they answered No to the first premium bid, the subsequent question posed a bid lower than the initial (still a premium over option A).

Respondents who chose option A (i.e., the ground beef with only the standard label) were asked whether they would be willing to purchase option B at a discount, if that were their only choice. For participants who answered Yes, a variant of the DBCV was used to determine the discount amounts these participants would be willing to accept to purchase the ground beef in option B. Those who were not willing to purchase option $\mathrm{B}$ at a discount were requested to provide a reason for this choice. Figure 1 depicts participants' labeling choice.

Following findings in the literature about loss of information and efficiency when more than six bid values are used (Creel 1998; Hanemann and Kanninen 2001), five premium bid values were considered sufficient. The bid values used as premiums were $\$ 0.40, \$ 0.80, \$ 1.20, \$ 2.00$, and $\$ 3.00$ while the bid values used as discounts were $\$ 0.20$, $\$ 0.40, \$ 0.80, \$ 1.20$, and $\$ 1.50$. The premium bids chosen are shown in Table 1.

Participants who chose option A were assigned two discount bids, with the second discount amount conditioned on the first, similar to the premium bid assignments. ${ }^{3}$ The discount amounts used are shown in Table 2.

\section{Empirical models}

\section{Multinomial logit model}

The multinomial logit was used to model individual choice among $J$ alternatives as a function of their characteristics (Hoffman and Duncan 1988). Participants are assumed to be utility maximizers and choose the option that yields the highest utility. Let $U_{i j}$ be an individual's indirect utility function for a given option, expressed as:

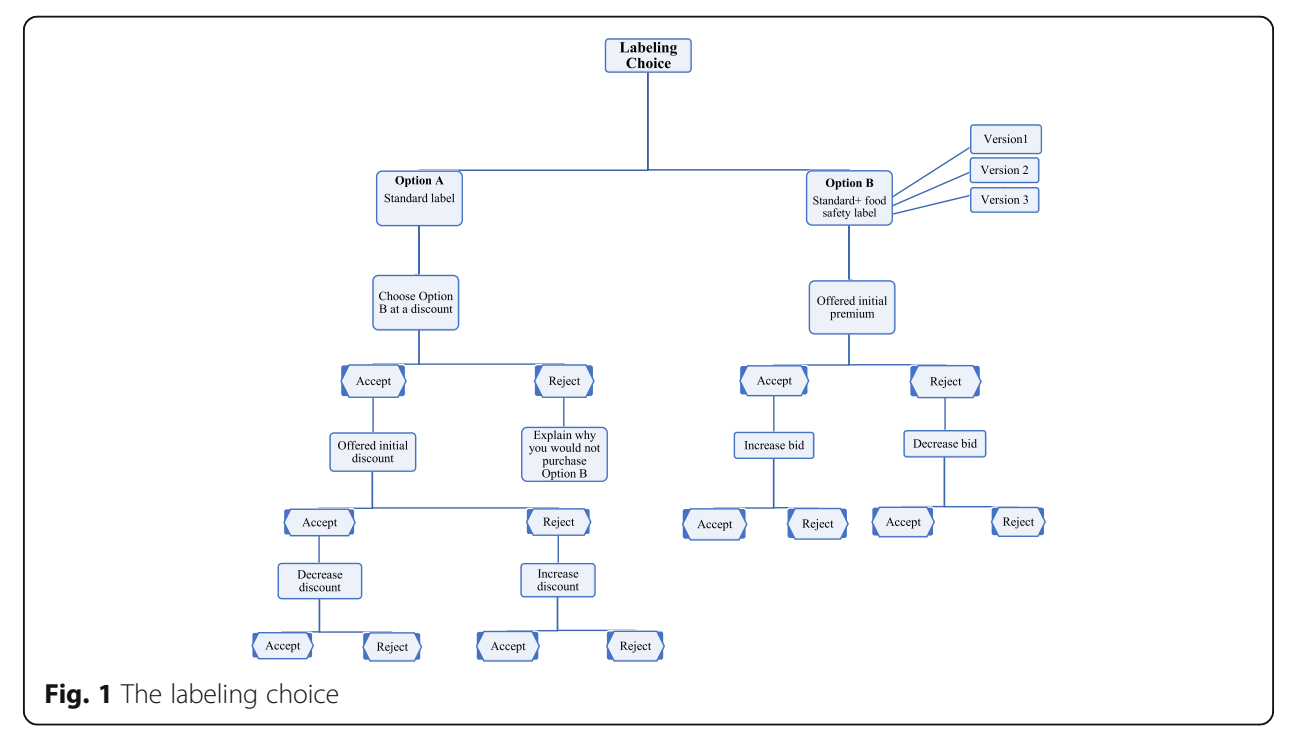




$$
U_{i j}=x_{i}^{\prime} \beta_{j}+\varepsilon_{i}
$$

where the subscript $i$ represents an individual, and $j$ the alternative. The vector $x_{i}$ captures the individual $i$ 's characteristics, and $\varepsilon_{i}$ the random error term which consists of unidentified factors that influence a participant's choice, and is independently and identically distributed with an extreme value type 1 distribution. Since an individual's true utility cannot be observed, the probability of a choice is used as a proxy in the estimation and is given as:

$$
\operatorname{Prob}\left\{y_{i}=j\right\}=\operatorname{Prob}\left\{\operatorname { m a x } \left(U_{\left.\left.i 1, \ldots \ldots, U_{i J}\right)\right\}}\right.\right.
$$

The probability that individual $i$ chooses alternative $j$, as shown by McFadden (1974), is:

$$
\operatorname{Prob}\left(y_{i}=j \mid x_{i}\right)=\frac{e^{x_{i}^{\prime} \beta_{j}}}{\sum_{k=1}^{J} e^{x_{i}^{\prime} \beta_{k}}}
$$

Equation 3 is the multinomial logit model. For this study, the ground beef with the standard label (option A) was designated as the reference or base category, with its probability given as:

$$
\operatorname{Prob}\left(y_{i}=1 \mid x_{i}\right)=\frac{1}{1+\sum_{k=1}^{J} e^{x_{i}^{\prime} \beta_{k}}}
$$

The odds ratio of individual $i$ choosing alternative $j$ is:

$$
\frac{\operatorname{Prob}\left(y_{i}=j\right)}{\operatorname{Prob}\left(y_{i}=1\right)}=\exp \left(x_{i}^{\prime} \beta_{j}\right)
$$

The multinomial logit model was estimated using the maximum likelihood procedure.

\section{Double-bounded contingent valuation method}

The contingent valuation method measures changes to an individual's expenditure function, or their indirect utility function. An individual faced with a well-behaved utility function subject to an income constraint maximizes their utility given as:

$$
v(p, q, y)=\max \{u(x, q) \mid p x \leq y\}
$$

where $x$ is a vector of private goods, such as ground beef; $q$ is an attribute associated with the quality/safety of the good; and $y$ is the individual's income. Using the compensating variation measure, we can determine the amount the individual is willing to pay for an improvement in the safety of the existing good from $q^{0}$ (ground beef without the

Table 1 Premium bids used

\begin{tabular}{lll}
\hline Initial bid & Lower bid (if answered NO to initial bid) & Higher bid (if answered YES to initial bid) \\
\hline$\$ 0.80$ & $\$ 0.40$ & $\$ 1.20$ \\
$\$ 1.20$ & $\$ 0.80$ & $\$ 2.00$ \\
$\$ 2.00$ & $\$ 1.20$ & $\$ 3.00$ \\
\hline
\end{tabular}


Table 2 Discount bids used

\begin{tabular}{lll}
\hline Initial discount & Lower discount (if YES to initial discount offer) & Higher discount (if NO to initial discount offer) \\
\hline$\$ 0.40$ & $\$ 0.20$ & $\$ 0.80$ \\
$\$ 0.80$ & $\$ 0.40$ & $\$ 1.20$ \\
$\$ 1.20$ & $\$ 0.80$ & $\$ 1.50$ \\
\hline
\end{tabular}

food safety enhancing attribute) to $q^{1}$ (ground beef with the food safety enhancing attribute), defined as:

$$
v\left(p, q^{1}, y-W T P\right)=v\left(p, q^{0}, y\right)
$$

where $q^{1}>q^{0}$ such that $\partial V / \partial q>0$. If the cost of the food safety attribute is $t$, the individual will agree to pay this amount only if their $W T P \geq t$. For the DBCV method, bivariate dichotomous choice valuation questions are asked resulting in four outcomes. Responses may fall into one of these four categories:

i. Yes to both bids (yes, yes)

ii. Yes to the first bid and no to the second (yes, no)

iii. No to the first bid and yes to the second bid (no, yes), and

iv. No to both bids (no, no).

Assume that $t^{1}$ and $t^{2}$ are the two bid amounts and $W T P_{i}$ represents a participant's WTP a premium price for ground beef with the additional food safety label. Following Hanemann et al. (1991) and Lopez-Feldman (2012), answers to the two valuation questions will result in the following outcomes:

$$
D_{i}=\left\{\begin{array}{c}
t^{2} \leq W T P_{i}<\infty, \text { if yes to both bids } \\
t^{1} \leq W T P_{i}<t^{2}, \text { if yes to first bid and no to second } \\
t^{2} \leq W T P_{i}<t^{1}, \text { if no to first bid and yes to second } \\
W T P_{i}<t^{2}, \text { if no to both bids }
\end{array}\right.
$$

Let a participant's WTP be defined as:

$$
W T P_{i}=z_{i}^{\prime} \beta+\varepsilon_{i}
$$

where $z_{i}$ is a vector of independent variables, $\beta$ is a vector of estimable parameters and $\varepsilon_{i}$ a random error term which is normally distributed with a constant variance $\left\{\varepsilon_{i} \sim N\left(0, \sigma^{2}\right)\right\}$. The log likelihood function for $N$ participants is given as:

$$
\begin{aligned}
\ln L & =\sum_{i=1}^{N}\left[I_{i}^{\text {yes,yes }} \ln \left(\Phi\left(\frac{z_{i}^{\prime} \beta-t^{2}}{\sigma}\right)\right)+I_{i}^{\text {yes,no }} \ln \left(\Phi\left(\frac{z_{i}^{\prime} \beta-t^{1}}{\sigma}\right)-\Phi\left(\frac{z_{i}^{\prime} \beta-t^{2}}{\sigma}\right)\right)\right. \\
& \left.+I_{i}^{\text {no,yes }} \ln \left(\Phi\left(\frac{z_{i}^{\prime} \beta-t^{2}}{\sigma}\right)-\Phi\left(\frac{z_{i}^{\prime} \beta-t^{1}}{\sigma}\right)\right)+I_{i}^{\text {no, no }} \ln \left(1-\Phi\left(\frac{z_{i}^{\prime} \beta-t^{2}}{\sigma}\right)\right)\right]
\end{aligned}
$$

$I_{i}^{\text {yes, yes }}, I_{i}{ }^{\text {yes, no }}, I_{i}^{\text {no, yes }}$, and $I_{i}^{\text {no, no }}$ are indicator variables equal to 0 or 1 , depending on the outcome for each participant.

Despite the advantages of the double-bounded model, starting point bias can reduce the efficiency of the WTP estimates, with implications for statistical inference (Herriges and Shogren 1996). When participants anchor their WTP to the starting point bid, the 
follow-up question becomes a weighted average of a respondent's prior WTP and the initial bid (Herriges and Shogren 1996), given as:

$$
W T P_{2}=W T P_{1}(1-\gamma)+\gamma t^{1}
$$

where $0 \leq \gamma \leq 1$ is the anchoring weight placed on the initial bid $t^{1}, W T P_{1}$ is the prior WTP, and $W T P_{2}$ is the posterior WTP.

A second potential violation of the double-bounded model is the shift effect (Alberini et al. 1997; Whitehead 2002). As expounded by Alberini et al. (1997), shift effect occurs when a participant's WTP shifts between the two responses, which means the follow-up valuation questions do not induce subjects to reveal their true WTP. In the presence of a shift effect, a subject's true WTP is equal to their stated WTP with a shift (Whitehead 2002), given as:

$$
W T P_{2}=W T P_{1}+\delta
$$

where $\delta$ is the shift parameter. In the presence of both shift and anchoring effects (starting point bias), WTP for the follow-up question becomes:

$$
W T P_{2}=W T P_{1}(1-\gamma)+\gamma t^{1}+\delta
$$

Both starting point bias and shift effect were accounted for in the empirical estimation. Starting point bias was controlled for by using two approaches, the first proposed by Chien et al. (2005) and the second by Whitehead (2002). Following Chien et al. (2005), two bid set dummies were constructed and included in the model for the three premium bid sets shown in Table 1 . The last bid set (\$2.00, \$1.20, and \$3.00) was assigned as the reference dummy. Following Alberini et al. (1997) and Whitehead (2002), the shift effect was empirically determined as the coefficient of a dummy variable equal to 1 for the follow-up question, and 0 otherwise, following the transformation of the data into a quasi-panel dataset. The starting point bias which is determined by the anchoring weight $\gamma$ is the coefficient of the interaction between the dummy variable on the follow-up question and the starting point bid.

\section{Results and discussion}

\section{Sample characteristics}

Table 3 displays descriptive statistics of participants' responses. Demographic variables show that $93 \%$ of respondents were principal household grocery shoppers, an outcome we anticipated given that the surveys were conducted in grocery stores. About $82 \%$ of respondents had at least some college background, higher than the $72 \%$ reported for the city of Lincoln (U.S. Census Bureau 2016). Average household income was approximately $\$ 57,000$, indicating a slight right skew compared to the city's median household income of approximately $\$ 56,000$. The majority of subjects were females, consistent with the observation that females are more likely to be principal grocery shoppers (Bureau of Labor Statistics 2017).

\section{Preferences for ground beef labels}

Table 4 reports statistics of respondents' choices based on the type of labels they were exposed to. The most chosen food safety label was the "unsubstantiated version" that provided no support for the food safety claims made (Safer Choice/Enhance). Nearly 
$70 \%$ of participants in this group chose option B, with just about $15 \%$ of them choosing option A. A little over $60 \%$ of respondents who were exposed to the food safety label with the "Safer Choice" phrase and additional information describing that the ground beef originated from cattle vaccinated against E. coli bacteria (Safer Choice/Vaccinated) chose this option. The food safety label that was least preferred among the three was the version with the E. coli display with the diagonal strikethrough (E. coli/Vaccinated).

These findings are consistent with the positive opinions consumers sometimes associate with food labels without standardized interpretations or with ambiguous claims such as "All Natural" (Liu et al. 2017). What appears obvious, however, is that consumers' response may be stronger towards labels that highlight a contaminant they wish to avoid.

A chi-square test was used to test differences among the three options (i.e., option A, option B, will not purchase); the test result was significant at better than the $1 \%$ level (Table 4), indicating that differences in response among the food safety labels were not due to chance. Key demographic characteristics such as household income, age, and education were not statistically different from each other among participants in the three food safety label groups (see tests in section B of the Appendix). Consequently, it can be concluded that a participant's

Table 3 Descriptive statistics and variable definition

\begin{tabular}{|c|c|c|c|}
\hline Variable & Description & Mean & $\begin{array}{l}\text { Std. } \\
\text { Dev. }\end{array}$ \\
\hline \multicolumn{4}{|c|}{ Attitudes, knowledge, and opinion } \\
\hline $\begin{array}{l}\text { Personal health } \\
\text { issues }\end{array}$ & Food purchasing decision based on health issues, $1=$ never to $4=$ always & 2.81 & 0.85 \\
\hline Food labels & Food purchasing decision based on food labels, $1=$ never to $4=$ always & 2.85 & 0.81 \\
\hline Read labels & Frequency of reading food labels, $1=$ never to $4=$ always & 2.95 & 0.80 \\
\hline $\begin{array}{l}\text { Knowledge } \\
\text { vaccines }\end{array}$ & Knowledge of animal vaccines, $1=$ nothing to $4=$ a great deal & 2.33 & 0.95 \\
\hline $\begin{array}{l}\text { Accept } \\
\text { vaccines }\end{array}$ & $\begin{array}{l}\text { Acceptance of animal vaccines, } 1=\text { totally unacceptable to } 5=\text { totally } \\
\text { acceptable }\end{array}$ & 3.09 & 1.12 \\
\hline Burgers cooked & Preference of cooking beef burgers, $1=$ rare to $4=$ well done & 3.07 & 0.81 \\
\hline \multicolumn{4}{|c|}{ Opinion about the government's role } \\
\hline Label vaccines & $\begin{array}{l}\text { Meat from vaccinated cattle should be labeled, } 1=\text { strongly disagree to } 5= \\
\text { strongly agree }\end{array}$ & 3.91 & 1.11 \\
\hline Ensure safety & $\begin{array}{l}\text { Government should ensure safety of food, } 1=\text { strongly disagree to } 5= \\
\text { strongly agree }\end{array}$ & 4.14 & 1.13 \\
\hline $\begin{array}{l}\text { Mandate } \\
\text { vaccines }\end{array}$ & $\begin{array}{l}\text { Government should mandate the use of animal vaccines, } 1=\text { strongly } \\
\text { disagree to } 5=\text { strongly agree }\end{array}$ & 3.34 & 1.24 \\
\hline \multicolumn{4}{|l|}{ Demographics } \\
\hline $\begin{array}{l}\text { Primary } \\
\text { shopper }\end{array}$ & 1 if subject does most of household grocery shopping, 0 otherwise & 0.93 & 0.26 \\
\hline $\begin{array}{l}\text { Children at } \\
\text { home }\end{array}$ & 1 if subject lives with children under 18 years of age, 0 otherwise & 0.38 & 0.49 \\
\hline College & 1 if subject has some college education or higher, 0 otherwise & 0.82 & 0.38 \\
\hline Male & 1 if subject is male, 0 female & 0.40 & 0.49 \\
\hline White & 1 if subject's ethnicity is white, 0 otherwise & 0.71 & 0.45 \\
\hline Income & Household income, in thousands & 57.32 & 51.13 \\
\hline Age & Age in years & 46.49 & 16.66 \\
\hline
\end{tabular}


Table 4 Statistics of subjects' response to ground beef options

\begin{tabular}{lllll}
\hline & Option A & Option B & Not purchase & Total \\
\hline Safer choice/Enhance & 22 & 101 & 23 & 146 \\
& $15.07 \%$ & $69.18 \%$ & $15.75 \%$ & $100.00 \%$ \\
Safer choiceNaccinated & 34 & 91 & 23 & 148 \\
& $22.97 \%$ & $61.49 \%$ & $15.54 \%$ & $100.00 \%$ \\
E. coliNaccinated & 56 & 71 & 24 & 151 \\
& $37.09 \%$ & $47.02 \%$ & $15.89 \%$ & $100.00 \%$ \\
Total & 112 & 263 & 70 & 445 \\
& $25.17 \%$ & $59.10 \%$ & $15.73 \%$ & $100.00 \%$ \\
\hline
\end{tabular}

Pearson Chi-square $=21.11, p$ value $=0.000$

choice was influenced by the type of food safety label they were exposed to. Furthermore, the fact that the proportion of respondents who chose the not-purchase option was almost identical (approximately 15\%) for each group provides additional support to the robustness of the experimental design.

\section{Multinomial logit results}

Results from the multinomial logit model refer to choices for the ground beef with the standard label (option A), the standard label plus a food safety label (option B), and the option to purchase neither. Option A was designated as the reference category, with results displayed in Table 5 showing both the estimates for the regressors as well as the odds ratios.

Compared to the group who saw the E. coli/Vaccinated label version (the reference category), those in the Safer Choice/Enhance or Safer Choice/Vaccinated versions were more likely to choose option B relative to option A. Being in the Safer Choice/Enhance group, which provided no justification for the safety claims made, significantly increased the odds of participants choosing option B. Participants in this group were 4.41 times more likely to choose option B relative to option A and 2.45 times more likely to choose the neither option compared to option A, both significant at the $5 \%$ level or better. Participants in the Safer Choice/Vaccinated group were also more likely to choose option B, although the odds ratio for this group at 1.89 was lower than the Safer Choice/Enhance group. The fact that participants who received the "unsubstantiated" food safety label (Safer Choice/Enhance) without the words "vaccines" or "E. coli" were more likely to choose this version, compared to those who were exposed to the more informative labeling versions, suggests the importance of the nature of information on food labels in influencing consumer choice.

Participants who frequently read food labels were 1.75 times more likely to choose neither beef option, compared to option $\mathrm{A}$, and 1.79 times more likely to choose option B. As expected, participants who are accepting of animal vaccines were more likely to choose option B, with a $51 \%$ increase in their odds. Although significant at the $10 \%$ level, the more participants preferred their beef burgers well cooked, the more likely they were to choose option B relative to option A. While it cannot be concluded that consumers who like their beef burgers well-cooked do so predominantly for safety reasons, this result indicates some level of association between such preferences and choosing the ground beef in option B. 
Table 5 Multinomial logit results for the labeling choices

\begin{tabular}{|c|c|c|c|c|}
\hline \multirow[b]{2}{*}{ Parameter } & \multicolumn{2}{|c|}{ Choose option B } & \multicolumn{2}{|c|}{ Choose neither option } \\
\hline & Estimate & Odds ratio & Estimate & Odds ratio \\
\hline Intercept & $\begin{array}{l}-5.7008^{* * *} \\
(1.2621)\end{array}$ & & $\begin{array}{l}-7.1452^{* * *} \\
(1.9240)\end{array}$ & \\
\hline \multicolumn{5}{|l|}{ Food safety label } \\
\hline Safer Choice/Enhance & $\begin{array}{l}1.4835^{* * *} \\
(0.3379)\end{array}$ & 4.4082 & $\begin{array}{l}0.8948^{* *} \\
(0.4413)\end{array}$ & 2.4468 \\
\hline Safer Choice/Naccinated & $\begin{array}{l}0.6361^{* *} \\
(0.2955)\end{array}$ & 1.8890 & $\begin{array}{l}0.3139 \\
(0.4082)\end{array}$ & 1.3687 \\
\hline \multicolumn{5}{|c|}{ Attitudes, knowledge, and opinion } \\
\hline Personal health issues & $\begin{array}{l}-0.0794 \\
(0.1677)\end{array}$ & 0.9236 & $\begin{array}{l}0.0957 \\
(0.2299)\end{array}$ & 1.1004 \\
\hline Food labels & $\begin{array}{l}-0.2440 \\
(0.2006)\end{array}$ & 0.7835 & $\begin{array}{l}-0.1266 \\
(0.2723)\end{array}$ & 0.8811 \\
\hline Read labels & $\begin{array}{l}0.5847^{* * *} \\
(0.2146)\end{array}$ & 1.7943 & $\begin{array}{l}0.5600^{* *} \\
(0.2831)\end{array}$ & 1.7506 \\
\hline Knowledge vaccines & $\begin{array}{l}-0.0622 \\
(0.1537)\end{array}$ & 0.9397 & $\begin{array}{l}0.1232 \\
(0.2012)\end{array}$ & 1.1311 \\
\hline Accept vaccines & $\begin{array}{l}0.4118^{* * *} \\
(0.1269)\end{array}$ & 1.5095 & $\begin{array}{l}-0.1780 \\
0.1610\end{array}$ & 0.8369 \\
\hline Burgers cooked & $\begin{array}{l}0.3146^{*} \\
(0.1657)\end{array}$ & 1.3697 & $\begin{array}{l}0.2283 \\
0.2258\end{array}$ & 1.2564 \\
\hline \multicolumn{5}{|c|}{ Opinion about the government's role } \\
\hline Label vaccines & $\begin{array}{l}0.3373^{* * *} \\
(0.1174)\end{array}$ & 1.4012 & $\begin{array}{l}0.4429^{* * *} \\
(0.1652)\end{array}$ & 1.5573 \\
\hline Mandate vaccines & $\begin{array}{l}0.3745^{* * *} \\
(0.1156)\end{array}$ & 1.4543 & $\begin{array}{l}-0.0590 \\
(0.1420)\end{array}$ & 0.9427 \\
\hline \multicolumn{5}{|l|}{ Demographics } \\
\hline Primary shopper & $\begin{array}{l}0.5572 \\
(0.4433)\end{array}$ & 1.7458 & $\begin{array}{l}1.0779 \\
(0.8256)\end{array}$ & 2.9384 \\
\hline Child at home & $\begin{array}{l}-0.2690 \\
0.2877\end{array}$ & 0.7641 & $\begin{array}{l}-0.3787 \\
0.3928\end{array}$ & 0.6848 \\
\hline College & $\begin{array}{l}0.17164 \\
(0.3487)\end{array}$ & 1.1873 & $\begin{array}{l}0.4403 \\
0.5043\end{array}$ & 1.5532 \\
\hline Male & $\begin{array}{l}0.6240^{* *} \\
(0.2820)\end{array}$ & 1.8664 & $\begin{array}{l}0.1070 \\
0.3894\end{array}$ & 1.1129 \\
\hline Income & $\begin{array}{l}0.0067^{* *} \\
(0.0031)\end{array}$ & 1.0068 & $\begin{array}{l}0.0031 \\
0.0041\end{array}$ & 1.0031 \\
\hline Age & $\begin{array}{l}-0.0132 \\
(0.0087)\end{array}$ & 0.9869 & $\begin{array}{l}-0.0064 \\
0.0117\end{array}$ & 0.9936 \\
\hline \multicolumn{5}{|l|}{ Location } \\
\hline Shopping district & $\begin{array}{l}0.0438 \\
(0.3799)\end{array}$ & 1.0448 & $\begin{array}{l}1.2766 \\
0.8286\end{array}$ & 3.5846 \\
\hline Natural foods store & $\begin{array}{l}0.1319 \\
(0.4312)\end{array}$ & 1.1410 & $\begin{array}{l}2.0621^{* *} \\
0.8264\end{array}$ & 7.8628 \\
\hline Urban center & $\begin{array}{l}-0.2527 \\
(0.4334)\end{array}$ & 0.7767 & $\begin{array}{l}1.6943^{* *} \\
0.8566\end{array}$ & 5.4429 \\
\hline
\end{tabular}

Standard errors are given in parentheses

Reference category: Option A (ground beef with only the standard label)

*Estimated coefficient is significant at the $10 \%$ level. ${ }^{* *}$ At the $5 \%$ significance level. ${ }^{* * *}$ At the $1 \%$ significance level

Participants who wanted beef products from vaccinated cattle labeled as such were 1.40 times more likely to choose option B and had a 56\% increase in their odds of choosing neither of the two options, relative to option A. It can thus be inferred that 
consumers in the latter group might prefer having the vaccine intervention indicated on a beef label to avoid it, likely the result of their concerns about the intervention. This result is similar to findings by Lusk and Fox (2002) who found a strong demand to mandatorily label beef products treated with hormones. Another interesting finding is that participants who wanted vaccines against $E$. coli to be mandatorily adopted had a $45 \%$ increase in their odds of choosing option B, relative to option A. This finding combined with the preference for labeling beef with the vaccine intervention among participants who chose option B or neither of the two options highlights the fact that consumers can have competing motivations when they demand food labeling. As argued by Messer et al. (2017), food process labels can lessen asymmetric information between producers and consumers. Thus, while food labels make it easier for consumers to purchase their preferred product, there are also consumer segments whose clamor for a label is to have a signal to avoid the product altogether (Liaukonyte et al. 2015). Regarding demographics, male and income were the two variables that emerged significant at the $5 \%$ level. Males were more likely to choose option B, and household income did not increase the odds of choosing option B over option A.

Finally, to examine the effect of grocery store location on preferences, the two grocery stores situated in the suburban neighborhoods were considered as one and assigned as the reference category. Relative to the grocery stores in the suburban neighborhoods, shoppers in the natural foods store were 7.86 times more likely to choose neither of the ground beef options, relative to option A. Even though this is not an entirely surprising finding, it also suggests that these consumers would be more difficult to convince concerning food safety technologies. In a similar result, shoppers in the store located in the urban center were also more likely to opt for neither of the two ground beef options, compared to shoppers in the suburban communities.

\section{Double-bounded contingent valuation results}

Responses from 263 participants who chose option B only (i.e., the ground beef with a standard label plus a food safety label) were analyzed using the DBCV method, results of which are shown in Table 6. Three variations of the model were estimated. First, a basic model (model I) which did not control for anchoring (starting point bias) and shift effects was estimated. The second model (model II) controls for starting point bias using Chien et al.'s (2005) approach with the bid set dummies, while the third model (model III) controls for both anchoring and shift effects following Alberini et al. (1997) and Whitehead (2002). The coefficients of the bid set dummies in model II are both statistically significant at better than the $1 \%$ level, an indication of starting point bias in the data. The coefficients of the anchoring weight $(\gamma)$ and the shift parameter $(\delta)$ in model III are also statistically significant at better than the $1 \%$ level. The positive coefficient of the anchoring weight parameter suggests that response to the second bid was anchored to the first (Herriges and Shogren 1996; Whitehead 2002). The significant shift effect parameter also indicates that subjects' WTP shifted between the two valuation questions.

Respondents randomly assigned to the Safer Choice/Enhance food label were willing to pay more, in both models II and III, compared to respondents who saw the E. coli/ Vaccinated label (the reference category), a further indication that the food safety label with no justification for the food safety claims was more appealing. The coefficient of 
Table 6 Results from double-bounded contingent valuation

\begin{tabular}{|c|c|c|c|}
\hline & $\begin{array}{l}\text { Model I } \\
\text { standard model }\end{array}$ & $\begin{array}{l}\text { Model II } \\
\text { with bid set dummies }\end{array}$ & $\begin{array}{l}\text { Model III } \\
\text { anchoring and shift }\end{array}$ \\
\hline Variable & Estimate & Estimate & Estimate \\
\hline Intercept & $\begin{array}{l}-0.405 \\
(0.701)\end{array}$ & $\begin{array}{l}0.081 \\
(0.594)\end{array}$ & $\begin{array}{l}-0.363 \\
(0.461)\end{array}$ \\
\hline \multicolumn{4}{|l|}{ Food safety label } \\
\hline Safer Choice/Enhance & $\begin{array}{l}0.324 \\
(0.209)\end{array}$ & $\begin{array}{l}0.346^{* *} \\
(0.175)\end{array}$ & $\begin{array}{l}0.328^{* *} \\
(0.137)\end{array}$ \\
\hline Safer Choice/Vaccinated & $\begin{array}{l}0.155 \\
(0.210)\end{array}$ & $\begin{array}{l}0.183 \\
(0.176)\end{array}$ & $\begin{array}{l}0.174 \\
(0.138)\end{array}$ \\
\hline \multicolumn{4}{|c|}{ Attitudes, knowledge, and opinion } \\
\hline Personal health issues & $\begin{array}{l}0.329^{* * *} \\
(0.109)\end{array}$ & $\begin{array}{l}0.255^{* * *} \\
(0.091)\end{array}$ & $\begin{array}{l}0.296^{* * *} \\
(0.071)\end{array}$ \\
\hline Read labels & $\begin{array}{l}0.100 \\
(0.120)\end{array}$ & $\begin{array}{l}0.098 \\
(0.101)\end{array}$ & $\begin{array}{l}0.097 \\
(0.079)\end{array}$ \\
\hline Accept vaccines & $\begin{array}{l}-0.163^{* *} \\
(0.082)\end{array}$ & $\begin{array}{l}-0.132^{*} \\
(0.069)\end{array}$ & $\begin{array}{l}-0.151^{* * *} \\
(0.054)\end{array}$ \\
\hline \multicolumn{4}{|c|}{ Opinions about the government's role } \\
\hline Label vaccines & $\begin{array}{l}0.230^{* *} \\
(0.099)\end{array}$ & $\begin{array}{l}0.233^{* * *} \\
(0.084)\end{array}$ & $\begin{array}{l}0.229^{* * *} \\
(0.065)\end{array}$ \\
\hline Mandate vaccines & $\begin{array}{l}0.062 \\
(0.081)\end{array}$ & $\begin{array}{l}0.028 \\
(0.068)\end{array}$ & $\begin{array}{l}0.049 \\
(0.053)\end{array}$ \\
\hline Ensure safety & $\begin{array}{l}-0.069 \\
(0.090)\end{array}$ & $\begin{array}{l}-0.024 \\
(0.076)\end{array}$ & $\begin{array}{l}-0.052 \\
(0.059)\end{array}$ \\
\hline \multicolumn{4}{|l|}{ Demographics } \\
\hline College & $\begin{array}{l}-0.431^{*} \\
(0.228)\end{array}$ & $\begin{array}{l}-0.267 \\
(0.192)\end{array}$ & $\begin{array}{l}-0.364^{* *} \\
(0.150)\end{array}$ \\
\hline Income & $\begin{array}{l}0.003^{*} \\
(0.002)\end{array}$ & $\begin{array}{l}0.002 \\
(0.001)\end{array}$ & $\begin{array}{l}0.002^{* *} \\
(0.001)\end{array}$ \\
\hline Children at home & $\begin{array}{l}0.093 \\
(0.174)\end{array}$ & $\begin{array}{l}0.091 \\
(0.146)\end{array}$ & $\begin{array}{l}0.098 \\
(0.114)\end{array}$ \\
\hline \multicolumn{4}{|l|}{ Location } \\
\hline Shopping district & $\begin{array}{l}0.454^{*} \\
(0.242)\end{array}$ & $\begin{array}{l}0.370^{*} \\
(0.207)\end{array}$ & $\begin{array}{l}0.389^{* *} \\
(0.159)\end{array}$ \\
\hline Natural Foods store & $\begin{array}{l}0.895^{* * *} \\
(0.272)\end{array}$ & $\begin{array}{l}0.732^{* * *} \\
(0.231)\end{array}$ & $\begin{array}{l}0.802^{* * *} \\
(0.178)\end{array}$ \\
\hline Urban center & $\begin{array}{l}0.725^{* * *} \\
(0.275)\end{array}$ & $\begin{array}{l}0.719^{* * *} \\
(0.233)\end{array}$ & $\begin{array}{l}0.702^{* * *} \\
(0.180)\end{array}$ \\
\hline \multicolumn{4}{|l|}{ Bid set dummies } \\
\hline Bid set 1 & & $\begin{array}{l}-0.841^{* * *} \\
(0.176)\end{array}$ & \\
\hline Bid set 2 & & $\begin{array}{l}-0.792^{* * *} \\
(0.164)\end{array}$ & \\
\hline \multicolumn{4}{|l|}{ Anchoring and shift effects } \\
\hline Anchoring $(\gamma)$ & & & $\begin{array}{l}0.711^{* * *} \\
(0.151)\end{array}$ \\
\hline Shift $(\delta)$ & & & $\begin{array}{l}-0.986^{* * *} \\
(0.234)\end{array}$ \\
\hline Log likelihood & -343.81 & -330.85 & -677.59 \\
\hline
\end{tabular}

Standard errors are given in parentheses

${ }^{*}$ Estimated coefficient is significant at the $10 \%$ level. ${ }^{* *}$ At the $5 \%$ significance level. ${ }^{* * *}$ At the $1 \%$ significance level 
the Safer Choice/Vaccinated label was not statistically significant, relative to the E.coli/ Vaccinated label version in all three model variations.

In relation to respondents' attitudes, knowledge, and opinion, those who rated personal health issues as important in food purchasing decisions were also willing to pay more for the ground beef with a food safety label. Being more accepting of the use of animal vaccines in food production lowered marginal WTP, which was significant in all three models at the $10 \%$ significance level or better. This outcome is somewhat surprising and indicates that support for a production process or attribute may not necessarily translate into a higher WTP for that attribute. Lusk and Fox (2002), for example, found that while consumers favored mandatory labels for beef products from hormone-induced cattle as well as cattle fed GM corn, they were reluctant to pay more to have such products differentiated. In our study, however, support for labeling vaccines translated into higher WTP in all three models.

Among demographics variables, college was statistically significant in models I and III at the $10 \%$ and $5 \%$ level of significance, respectively. Remarkably, the coefficient of this variable is negative, suggesting that respondents with a college background or better were not willing to pay more for ground beef with a food safety label. Although this finding may require further investigation, the fact that more educated respondents would pay less does not necessarily indicate their aversion for the food safety label or the vaccine intervention. It could suggest that highly educated respondents were likely to be skeptical about the E. coli reduction claim from vaccine use on the food safety label, or the unsupported claim about enhanced safety from cattle raised under strict health standards, to warrant an extra cost to them. Strijbos et al. (2016) reported that among their sample of Dutch residents who participated in a study examining health claims of reduced nitrate levels in meat, those with relatively lower educational backgrounds were more likely to perceive such claims to be credible. The statistically significant income variable in models I and III indicates a higher WTP among respondents with high household incomes.

The grocery store location variables were significant in all three models at the $10 \%$ level or better, relative to the suburban locations designated as the reference category. ${ }^{4}$ Shoppers sampled from the grocery store in the urban center had a higher marginal WTP for a food safety label relative to those in the suburban location. An interesting finding is that marginal contribution to WTP of natural food shoppers surpassed those sampled from the grocery stores in the shopping district and the urban center, relative to shoppers from stores located in the suburban neighborhoods. It is plausible to postulate that natural food shoppers are more concerned about healthy foods; thus, those in this group who chose the ground beef in option B were also willing to pay more for it.

Associated mean WTP estimates for each of the three food safety label versions given individual characteristics are displayed in Table 7, using results from model III only. The highest average price premium of $\$ 1.77$ was recorded for the ground beef with the unsubstantiated food safety claim (Safer Choice/Enhance). Participants exposed to the Safer Choice/Vaccinated food safety label were willing to pay an average of \$1.62 more for this option.

A noteworthy finding is the response from participants in the group who saw the $E$. coli/Vaccinated food safety label version, who were willing to pay $\$ 1.44$ as price 
premium for a pound of ground beef with this label, approximately 19\% lower than the price premium for the food safety label without the words "vaccines" or "E. coli" (Safer Choice/Enhance). While the 95\% confidence interval for the Safer Choice/Vaccinated food label overlaps with the Safer Choice/Enhance version, the latter overlaps only slightly with the confidence interval for the E. coli/Vaccinated food safety label.

Overall, our results show that food labels that make unsubstantiated claims of food safety could command higher premiums, compared to labels that offer factual and accurate information to substantiate food safety claims. As in Syrengelas et al. (2017) who found that beef consumers were willing to pay a price premium for steak with a "natural" labeling claim when they were uninformed about the USDA definition of natural, in our study, consumers faced with unsupported, positive food safety claims may be overestimating what these claims promise. Consumers may be interpreting the unsupported claim on the Safer Choice/Enhance label to imply protection against a number of harmful diseases, not just against E. coli as with the other two labeling options. ${ }^{5}$ Additionally, even though vaccine use in animal production has not attracted widespread public debate compared to other interventions and production processes, there are concerns about the health impacts of vaccinations in general and this might perhaps have influenced respondents' perceptions of ground beef products from vaccinated cattle. As Liaukonyte et al. (2013) note, positive information about contested food production processes may not be enough to mitigate consumer biases.

Additional insights can be gleaned by examining the differences in WTP between the Safer Choice/Vaccinated and E. coli/Vaccinated label versions. With similar descriptions, the only difference between these labeling versions was the display of "Safer Choice" or the encircled E. coli with the strikethrough. The fact that the latter was the least preferred, both in terms of respondents who chose this option or the average price premium they were willing to pay, could be suggestive of some form of a boomerang or reactance effect (Gifford and Bernard 2004). In this case, the display with the E. coli with the strikethrough intended to buttress the safety of the beef product from E. coli bacteria may have instead acted as a warning, emphasizing the risk from E. coli bacteria and crowding out the message that vaccines help lower this risk. ${ }^{6}$

Overall, consumers' WTP a price premium for ground beef with a food safety label option suggests that its presence in retail markets could potentially drive down the price of regular beef, similar to findings by Kanter et al. (2009) who showed in an experimental study that the presence of rBST-free milk reduced WTP for conventional milk.

Finally, there were 112 respondents who chose option A, representing $25.17 \%$ of the sample. Of this number, 65 participants were willing to purchase option B if they were offered a discount. The small number of these observations, however, did not allow for a very meaningful empirical analysis for this group. A table summarizing discount bids

Table 7 Estimates of mean WTP for the food safety labels

\begin{tabular}{llll}
\hline Mean WTP estimate & Safer Choice/Enhance & Safer Choice/Naccinated & E. coliNaccinated \\
\hline Mean WTP & $\$ 1.77$ & $\$ 1.62$ & $\$ 1.44$ \\
Lower $95 \% \mathrm{Cl}$ & $\$ 1.60$ & $\$ 1.44$ & $\$ 1.24$ \\
Upper $95 \% \mathrm{Cl}$ & $\$ 1.94$ & $\$ 1.79$ & $\$ 1.65$ \\
\hline
\end{tabular}


among participants is displayed in section $\mathrm{C}$ of the Appendix. Also included in the Appendix (section D) is a selection of comments from respondents explaining why they did not choose option B. It is important to note that approximately a quarter of respondents choosing the ground beef with the standard label also underscores the challenge in labeling food safety attributes. Among these participants, the majority indicated a willingness to purchase the ground beef with a food safety label at a discount if that was their only choice. Reasons given by respondents who were completely opposed to ground beef with a food safety label, and would not purchase it even at a discount, echoed their aversion for vaccinations for a variety of reasons. In general, the remarks given by these respondents revealed doubts about the food safety labels and insufficient knowledge of vaccines. This suggests the possibility of some consumers misinterpreting the information on the labels (Messer et al. 2017).

\section{Conclusions}

Despite evidence that consumers value safe food products, communicating food safety enhancing attributes/technologies on food labels is challenging, partly due to consumer apprehension and insufficient understanding of food safety interventions. Extending previous studies that show that consumers are willing to pay for specific food safety interventions when they are provided with information about them (Fox et al. 2002; Nayga Jr et al. 2006; Teisl and Roe 2010), this study explored diverse ways of communicating food safety attributes through labeling cues, on consumer choices, and WTP for such attributes. The study also examined the influence of individual characteristics on preferences for food safety labels. These objectives were achieved through a survey that asked shoppers to choose between two types of ground beef: one with a standard/generic label and one that, in addition to the standard label, also had a food safety label. Three of such food safety labels were designed, each providing different information about the food safety intervention, and randomly assigned to participants.

Results show that consumers were willing to pay a price premium for ground beef with a food safety label while the most preferred food safety label was the one that did not provide information about the intervention and its role in enhancing food safety. Results also show that preferences and WTP for safer foods are affected by demographic characteristics. For example, participants who had a high school education or less were willing to pay more for a food safety label, relative to those with higher educational backgrounds. We also found that some segments of consumers who chose the ground beef with a food safety label, such as natural food shoppers, were willing to pay a higher price for them, relative to shoppers in stores located in suburban neighborhoods. This suggests that having a good understanding of the demographic composition of the consumers that they target can help processors/retailers to more effectively use food labels to communicate food safety attributes.

For producers who may contemplate adopting the vaccine intervention or other costly food safety technologies, the prospect of commanding a price premium from identifying such interventions on food labels looks promising. Appealing to consumer segments who value these interventions will nevertheless require a tactful framing of information on food labels; one that simultaneously eases consumers' 
doubts (Kahan et al. 2007, 2008) and signals the enhanced safety of the product. Based on our results, labels with a positive but vague food safety message may appeal more to consumers than labels that emphasize the food safety risk that is mitigated, as the former are subject to a potential overestimation of the food safety benefits.

Finally, our findings suggest that even under a stricter labeling policy, one that would not allow unsupported claims on food labels but rather require explicit reference to the food safety interventions used to support these claims, producers adopting the vaccine intervention could effectively differentiate their products in the retail market and capture price premiums. Such a policy could also help inform and educate consumers about the technologies used in their food production. Our results should be interpreted with caution given the limited consumer pool used in the study, as well as its regional focus. Future research could further explore consumer attitudes towards different label designs and target a sample that better reflects the demographics of the USA.

\section{Endnotes}

${ }^{1}$ According to the 2012 Food and Health Survey by the International Food Information Council, 78\% of American consumers expressed confidence in the safety of foods in the United States (see http://www.foodinsight.org/Content/3848/ FINAL\%202012\%20Food\%20and\%20Health\%20Exec\%20Summary.pdf).

${ }^{2}$ The first grocery store was located in a suburban neighborhood, to help sample views from shoppers who live in the surrounding community. Shoppers in the second store were a demographically diverse mix, most likely a result of its location in a shopping district with adjoining shops and restaurants. The third and fourth grocery stores belonged to the same brand as the second, wherein the third store was situated in an urban center and the fourth was in a relatively new part of town surrounded by a shopping mall and suburban communities. The fifth store, a cooperative natural foods store, was chosen to represent consumers with preference for natural and organic food products.

${ }^{3}$ This set-up is similar to McCluskey et al. (2003), who posed a second question to respondents willing to purchase a genetically modified (GM) food product at the same price as the non-GM version. Respondents who answered Yes were asked whether they were also willing to purchase the GM product at a percentage premium, otherwise, at a discount.

${ }^{4}$ The location variables were interacted with the food safety label variables to investigate interaction effects between grocery store location and the type of food safety label shoppers chose. The interaction effects were not statistically significant in any of the three model variations, and a likelihood ratio test suggests that the interaction models were not significantly different from models without interaction.

${ }^{5}$ We would like to thank an anonymous reviewer for suggesting this possible explanation of our findings.

${ }^{6} \mathrm{~A}$ similar result is shown by Kahan et al. (2008) in a study that examines the effects of message framing on nanotechnology risk perceptions. The study found that messages that emphasized the potential of nanotechnology to mitigate alarming risks had the paradoxical effect of causing nanotechnology itself to be perceived as risky. 


\section{Appendix}

A. Food safety label versions

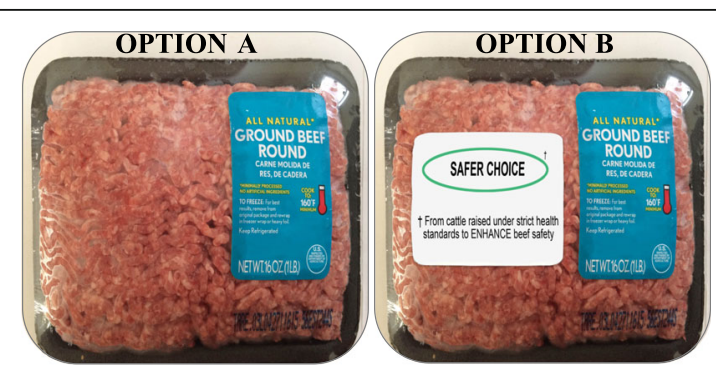

Fig. 2 First version of option B "Safer Choice/Enhance" provides no information about the food safety intervention used to support food safety claims.

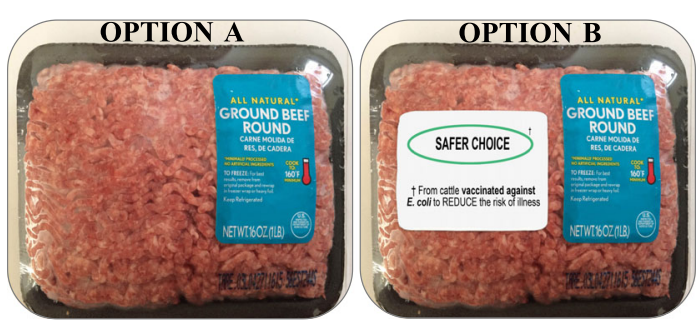

Fig. 3 Second version of option B "Safer Choice/Vaccinated" provides information about the food safety intervention to support food safety claims

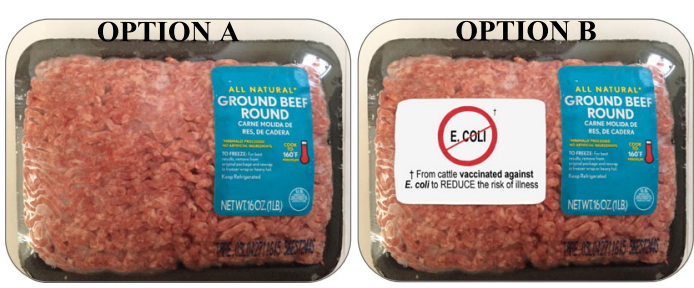

Fig. 4 Third version of option B "E. coliNaccinated" also provides information about the food safety intervention to support food safety claims

B. Demographic differences by food label version groups

\begin{tabular}{llll}
$\begin{array}{l}\text { Chi-square test-educational background } \\
\text { Food safety label }\end{array}$ & High school or less & Some college or higher & Total \\
\hline Safer Choice/Enhance & 22.32 & 77.68 & 100 \\
Safer Choice/Naccinated & 17.49 & 82.51 & 100 \\
E. coliNaccinated & 11.43 & 88.57 & 100 \\
Total & 17.75 & 82.25 & 100
\end{tabular}

Pearson chi-squared test $(2)=3.5309 \operatorname{Pr}=0.171$ 


\begin{tabular}{llllll}
\multicolumn{2}{l}{$\begin{array}{l}\text { Analysis of variance-household income } \\
\text { Source }\end{array}$} & SS & MS & F & Prob > F \\
\hline Between groups & 1544.19 & 2 & 772.095 & 0.29 & 0.7451 \\
Within groups & $1,156,541$ & 441 & 2622.543 & & \\
Total & $1,158,086$ & 443 & 2614.189 & & \\
& & & & F & Prob > F \\
Variance-age & SS & df & MS & 0.17 & \\
Source & & & & & \\
\hline & 93.29408 & 2 & 46.64704 & \\
Between groups & $123,106.4$ & 442 & 278.5213 & & \\
Within groups & $123,199.7$ & 444 & 277.4769 & & \\
Total & & & &
\end{tabular}

C. Willingness to accept a discount to choose option B

Table 8 in Appendix shows the count and frequency for the discount bids among participants who chose the ground beef with the standard label (option A), but indicated a willingness to purchase option B (standard label and a food safety label) only at a discounted price if that was their only choice. In total, there were 65 such respondents, which represents $15 \%$ of all participants, and $58 \%$ of those who chose option A.

Table 8 Count and frequency of discount response

\begin{tabular}{llll}
\hline Discount & Discount 2 & Yes & Total \\
\cline { 2 - 4 } & No & 6 & 12 \\
No & 6 & $12.24 \%$ & $18.46 \%$ \\
Yes & $37.50 \%$ & 43 & 53 \\
& 10 & $87.76 \%$ & $81.54 \%$ \\
Total & $65.50 \%$ & 49 & 65 \\
& 16 & $100.00 \%$ & $100.00 \%$ \\
\hline
\end{tabular}

D. Select comments concerning the food safety labels

Selection of comments from participants averse to the Safer Choice/Vaccinated label version

It looks scary

How do I know for sure what the cattle were vaccinated with?

I do not think $E$. coli vaccine prevents $E$. coli infections in meat

Only eat natural, grass fed, free to roam, farm raised beef with no antibiotics

I do not trust vaccinated meat

Selection of comments from participants averse to the E. coli/Vaccinated label version

It is not necessary to vaccinate for $E$. coli

Vaccines and medicinal treatments for animals are generally poor practices

E. coli can be killed using proper cooking and handling techniques

Just seeing the word E. coli turns me off

I do not like meat that is vaccinated

I only purchase "healthy" beef 
Acknowledgements

The authors are grateful to Stamatina Kotsakou for helping with the in-store surveys.

\section{Funding}

This research is based upon work that was supported by the National Institute of Food and Agriculture, U.S.

Department of Agriculture, under award 2012-68003-30155.

\section{Availability of data and materials}

Data and supporting materials for the study will be shared by the authors upon request.

\section{Authors' contribution}

$\mathrm{KB}$ and $\mathrm{AY}$ proposed and refined the research idea. $\mathrm{KB}$ conducted the in-store surveys and analyzed the data. AY was instrumental in the writing and editing of the manuscript. All authors read and approved the final manuscript.

\section{Ethics approval and consent to participate}

Not applicable

\section{Consent for publication}

Both authors consent to the publication of this research.

\section{Competing interests}

The authors declare that they have no competing interests.

\section{Publisher's Note}

Springer Nature remains neutral with regard to jurisdictional claims in published maps and institutional affiliations.

\section{Author details}

${ }_{1}^{1}$ Postdoctoral Research Associate, School of Economics, University of Maine, 5782 Winslow Hall, Orono, ME 04469, USA. 2Department of Agricultural Economics, University of Nebraska-Lincoln, 314B H.C. Filley Hall, Lincoln, NE 68583-0922, USA.

Received: 16 October 2017 Accepted: 20 January 2019

Published online: 20 February 2019

\section{References}

Alberini A, Kanninen B, Carson RT (1997) Modeling response incentive effects in dichotomous choice contingent valuation data. Land Econ 73:309-324

Bimbo F, Bonanno A, Viscecchia R (2016) Do health claims add value? The role of functionality, effectiveness and brand. Eur Rev Agric Econ 43:761-780

Bureau of Labor Statistics (2017) American time use survey summary. Available at https://www.bls.gov/news.release/atus.nr0. htm

Callaway TR, Carr MA, Edrington TS, Anderson RC, Nisbet DJ (2009) Diet, Escherichia coli O157: H7, and cattle: a review after 10 years. Current Issues in Mol Biol 11:67

Chien YL, Huang CJ, Shaw D (2005) A general model of starting point bias in double-bounded dichotomous contingent valuation surveys. J of Env Econ Manage 50:362-377

Creel M (1998) A note on consistent estimation of mean WTP using a misspecified logit contingent valuation model. J of Env Econ Manage 35:277-284

Dolgopolova I, Teuber R (2017) Consumers' willingness to pay for health benefits in food products: a meta-analysis. Appl Econ Perspect Policy 40:333-352

Fox JA, Hayes DJ, Shogren JF (2002) Consumer preferences for food irradiation: how favorable and unfavorable descriptions affect preferences for irradiated pork in experimental auctions. J Risk Uncertain 24:75-95

Gifford K, Bernard JC (2004) The impact of message framing on organic food purchase likelihood. J Food Distribution Res 35 : $19-28$

Hanemann M, Kanninen B (1999) The statistical analysis of discrete-response CV data. Valuing environmental preferences: theory and practice of the contingent valuation method in the US, EU, and developing countries. I.J. Bateman and K.G. Willis, ed. Oxford University Press 302-441

Hanemann M, Loomis J, Kanninen B (1991) Statistical efficiency of double-bounded dichotomous choice contingent valuation. Am J Agric Econ 73:1255-1263

Herriges JA, Shogren JF (1996) Starting point bias in dichotomous choice valuation with follow-up questioning. J Env Econ Manage 30:112-131

Hoffman SD, Duncan GJ (1988) Multinomial and conditional logit discrete-choice models in demography. Demography 25 : $415-427$

Huang CL, Wolfe K, McKissick J (2007) Consumers' willingness to pay for irradiated poultry products. J Int Food Agribusiness Mark 19:77-95

Hurd HS, Malladi S (2012) An outcomes model to evaluate risks and benefits of Escherichia coli vaccination in beef cattle. Foodborne Pathog Dis 9:952-961

Kahan DM, Kysar D, Braman D, Slovic P, Cohen G, Gastil J (2008) Cultural cognition of nanotechnology risk perceptions: an experimental investigation of message framing. Cultural cognition project, Available at http://citeseerx.ist.psu.edu/ viewdoc/download?doi=10.1.1.630.9866\&rep=rep1\&type=pdf 
Kahan DM, Slovic P, Braman D, Gastil J, Cohen GL (2007) Affect, values, and nanotechnology risk perceptions: an experimental investigation. Cultural cognition project working paper 22. Available at http://ssrn.com/abstract=968652

Kanter C, Messer KD, Kaiser HM (2009) Does production labeling stigmatize conventional milk? Am J Agric Econ 91:10971109

Lewis KE, Grebitus C, Colson G, Hu W (2017) German and British consumer willingness to pay for beef labeled with food safety attributes. J Agric Econ 68:451-470

Liaukonyte J, Streletskaya NA, Kaiser HM (2015) Noisy information signals and endogenous preferences for labeled attributes. J Agric Resour Econ 40(2):179-202

Liaukonyte J, Streletskaya NA, Kaiser HM, Rickard BJ (2013) Consumer response to "contains" and "free of" labeling: evidence from lab experiments. Appl Econ Perspect Policy 35:476-507

Liu R, Hooker NH, Parasidis E, Simons CT (2017) A natural experiment: using immersive technologies to study the impact of "all-natural" labeling on perceived food quality, nutritional content, and liking. J Food Sci 82:825-833

Lopez-Feldman A (2012) Introduction to contingent valuation using Stata. MPRA, p 41018. Available at http://mpra.ub.unimuenchen.de/41018/

Loureiro ML, McCluskey JJ (2000) Consumer preferences and willingness to pay for food labeling: a discussion of empirical studies. J Food Distribution Res 34:95-102

Lusk JL, Fox JA (2002) Consumer demand for mandatory labeling of beef from cattle administered growth hormones or fed genetically modified corn. J Agric Appl Econ 34:27-38

Matthews L, Reeve R, Gally DL, Low JC, Woolhouse MEJ, McAteer SP, Locking ME, Chase-Topping ME, Haydon DT, Allison LJ Hanson MF, Gunn GJ, Reid SWJ (2013) Predicting the public health benefit of vaccinating cattle against Escherichia coli 0157. Proceedings of the National Academy of Sciences of the United States of America (PNAS)

McCluskey JJ, Curtis KR, Li Q, Wahl TI, Grimsrud KM (2003) A cross-country consumer attitudes and willingness to pay for genetically modified foods comparison. Biotechnol:117-123

McFadden D (1974) In: Zaremka P (ed) Conditional logit analysis of qualitative choice behavior. Frontiers in econometrics. Academic press, New York

Messer KD, Costanigro M, Kaiser HM (2017) Labeling food processes: the good, the bad and the ugly. Appl Econ Perspect Policy 39:407-427

Nayga RM Jr, Woodward R, Aiew W (2006) Willingness to pay for reduced risk of foodborne illness: a non-hypothetical field experiment. Canadian J Agric Econ 54:461-475

Palma MA, Collart AJ, Chammoun CJ (2015) Information asymmetry in consumer perceptions of quality-differentiated food products. J Consum Aff 49:596-612

Strijbos C, Schluck M, Bisschop J, Bui T, De Jong I, Van Leeuwen M, von Tottleben M, van Breda SG (2016) Consumer awareness and credibility factors of health claims on innovative meat products in a cross-sectional population study in the Netherlands. Food Qual Prefer 54:13-22

Syrengelas KG, DeLong KL, Grebitus C, Nayga RM (2017) Is the natural label misleading? Examining consumer preferences for natural beef. Appl Econ Perspect Policy 40:445-460

Teisl MF, Roe BE (2010) Consumer willingness to pay to reduce the probability of retail foodborne pathogen contamination. Food Policy 35:521-530

Tonsor GT, Schroeder TC (2015) Market impacts of E. coli vaccination in US feedlot cattle. Agric Food Econ 3(1):7

U.S. Census Bureau (2016) American community survey 1-year estimates. Retrieved from Census Reporter Profile page for Lincoln, NE on February 17, 2018 https://censusreporter.org/profiles/16000US3128000-lincoln-ne/

Verbeke W, Ward RW (2006) Consumer interest in information cues denoting quality, traceability and origin: an application of ordered probit models to beef labels. Food Qual Prefer 17:453-467

Wang Q, Halbrendt C, Kolodinsky J, Schmidt F (1997) Willingness to pay for rBST-free milk: a two-limit tobit model analysis. Appl Econ Lett 4:619-621

Whitehead JC (2002) Incentive incompatibility and starting-point bias in iterative valuation questions. Land Econ 78:285-297

\section{Submit your manuscript to a SpringerOpen ${ }^{\circ}$ journal and benefit from:}

- Convenient online submission

- Rigorous peer review

- Open access: articles freely available online

- High visibility within the field

- Retaining the copyright to your article

Submit your next manuscript at $\mathbf{s p r i n g e r o p e n . c o m ~}$ 